\title{
Para um futuro de igualdade na América Latina, o direito de decidir
}

Marcelle Cristine de SouZA, Universidade de São Paulo

Este ensaio discute a criminalização do aborto como um dos grandes obstáculos para o pleno exercício da cidadania pelas mulheres na América Latina. A partir de revisão bibliográfica e de casos discutidos recentemente no Judiciário e Legislativo de países da Região, mostra o porquê a legalização do aborto é um tema emergente para garantir a igualdade de gênero em nossas sociedades. O texto ainda enumera os impactos da criminalização da prática na saúde pública, na economia e na vida de $97 \%$ das mulheres latino-americanas. Por fim, o ensaio aponta conquistas e caminhos já traçados em países da Região como forma de pensar um futuro de mudanças na América Latina.

PALAVRAS-CHAVE: Aborto. Igualdade de Gênero. América Latina. 
Quando a chamada Marea Verde inundou as ruas de cidades argentinas em 2018 em apoio ao projeto que visava a legalização do aborto até a $14^{\mathrm{a}}$ semana de gestação no país (ARGENTINA, 2018), o debate sobre o tema logo virou pauta também em outros lugares da América Latina. Em pouco tempo, os pañuelos verdes, adereço indispensável às feministas que saíram em defesa da mudança na lei na Argentina, começaram a ser vistos também em países como Chile, Peru, Equador, Colômbia, Brasil e México, como um símbolo que unia distintas realidades sob o lema "Educación sexual para decidir, anticonceptivos para no abortar y aborto legal para no morir", que estampava os lenços da campanha.

A repercussão da luta para além das fronteiras da Argentina tem uma explicação central: na América Latina e no Caribe são realizados 6,5 milhões de abortos por ano, o que significa 44 interrupções voluntárias a cada 1.000 mulheres em idade reprodutiva - taxa que supera os números da África, da Ásia e das demais regiões pesquisadas pelo Guttmacher Institute (2016). Uma das justificativa para índices tão altos de abortos, segundo a organização, é que a América Latina concentra as leis mais restritivas do mundo, empurrando mulheres todos os anos para a clandestinidade e aumentando a insegurança do procedimento.

Nesse contexto, como uma onda internacional, o debate na Argentina deu força a iniciativas semelhantes e protestos em várias cidades da Região. No Chile, o texto argentino incentivou a apresentação, por um grupo de nove deputadas, de um projeto que despenalizava o aborto até a $14^{\mathrm{a}}$ semana de gestação (CHILE, 2018). No Brasil, os pañuelos verdes dividiram espaço com lenços lilás (cor historicamente utilizada pelos feminismos no país) durante a audiência pública no STF (Supremo Tribunal Federal) sobre a ADPF 442 (BRASIL, 2017), ação protocolada pelo PSOL (Partido Socialismo e Liberdade) que questiona os artigos 124 e 126 do Código Penal e pede a legalização do aborto até $\mathrm{a} 12^{\mathrm{a}}$ semana de gestação no país.

De volta à Argentina, em agosto de 2018 os senadores acabaram por rejeitar a proposta sobre a interrupção voluntária da gravidez, minando temporariamente a esperança de que o avanço servisse de exemplo para outras Casas Legislativas na América Latina. Mas a luta não para por aí.

Segundo The World Abortion Laws Map, um relatório produzido desde 1998 pela organização Center for Reproductive Rights, em 2019 as 
leis sobre aborto na Região podiam ser agrupadas em quatro: o primeiro é formado pelos países que descriminalizaram a prática em caso de risco à vida da gestante (como Brasil, Chile, Venezuela e Paraguai); no segundo grupo estão os que proíbem completamente o aborto (caso de Honduras, El Salvador e Nicarágua); o terceiro é dos que permitem a interrupção da gravidez para preservar a saúde física e mental da gestante (entre eles, Argentina, Colômbia e Costa Rica); e, por fim, estão os países que legalizaram o aborto, com diferentes limites de idade gestacional, como Uruguai e Cuba.

Em outras palavras, 97\% das mulheres da América Latina vivem atualmente em países onde a prática é considerada um crime, exceto em poucos casos (GUTTMACHER INSTITUTE, 2016). O problema é que leis altamente restritivas não impedem que $75 \%$ dos 6,5 milhões de abortos induzidos sejam realizados de forma insegura a cada ano na Região (GANATRA ET AL, 2017). Se não evitam a prática, essas normas são muito eficazes em reforçar desigualdades e impactar de modo negativo a vida das latino-americanas, como afirma a antropóloga Débora Diniz (2007, p. 1992): "Na verdade, as poucas e seguras evidências disponíveis no cenário das pesquisas em saúde no Brasil comprovam a tese de que a ilegalidade traz consequências para a saúde das mulheres, que não coíbe a prática e perpetua a desigualdade social”.

Essas leis, portanto, significam barreiras importantes à igualdade de direitos entre homens e mulheres na América Latina, mas não só. Como mostraremos a seguir, a criminalização do aborto também acentua as desigualdades entre as mulheres (ricas e pobres, urbanas e rurais, brancas e negras ou indígenas). São discriminatórias porque expõem apenas uma parcela da população à prisão e ao risco de morte, entre outras consequências morais, sociais, econômicas de um aborto inseguro. Tais normas condenam mulheres e não protegem os fetos, já que os abortos (sejam legais ou ilegais) acontecem, como apontam os números da região. Na prática, elas ainda descumprem os documentos 
pactuados nas Conferências do Cairo $^{1}$ (UNFPA, 1994) e Pequim² (UNFPA, 1995), que reconhecem o aborto como um problema de saúde pública e recomendam a revisão da criminalização.

Para representantes da ONU (Organização das Nações Unidas), impedir o acesso a serviços de saúde reprodutiva dos quais apenas as mulheres precisam, entre eles o aborto, é inerentemente discriminatório e pode violar os compromissos firmados na Convenção contra Tortura:

Apesar de saberem que o aborto inseguro é uma das causas principais da mortalidade e morbidade maternas, alguns Estados continuam a aplicar uma proibição completa dos abortos ou leis de aborto altamente restritivas, forçando mulheres a (passar por) situações de desespero e perigo. (ZIELINSKA ET AL, 2016)

\section{Aborto Inseguro e os Impactos na Saúde Pública}

Clandestinos, os abortos provocados são a causa de $10 \%$ das mortes maternas e da internação de 760 mil mulheres por ano por complicações de procedimentos realizados à margem da lei e de modo inseguro na América Latina (GUTTMACHER, 2016). O número está acima da média mundial e só é semelhante ao da África Subsaariana. Não é coincidência o fato de que as duas regiões citadas estão no topo do ranking das que possuem leis mais restritivas em relação ao aborto (CENTER FOR REPRODUCTIVE RIGHTS, 2018).

Para a saúde pública, isso significa mulheres que chegam ao hospital com infecções, órgãos perfurados e que correm o risco de ficarem estéreis. Outras, nem viram número no sistema de saúde, como a brasileira Jandira, que em 2014 procurou uma clínica clandestina para fazer um aborto e desapareceu (BERTHO, 2017). Sem respaldo da fiscalização dos órgãos de saúde e de segurança, o procedimento deu errado e os responsáveis tentaram ocultar o crime. Dias depois, seu

\footnotetext{
1 Diz o Parágrafo 8.25 do relatório: "Todos os governos e organizações intergovernamentais e não-governamentais são instados a reforçar seus compromissos com a saúde da mulher, a considerar o impacto de um aborto inseguro na saúde como uma preocupação de saúde pública e a reduzir o recurso ao aborto, ampliando e melhorando os serviços de planejamento familiar" (UNFPA, 1994).

2 Conforme o Parágrafo 97 do relatório: "O aborto inseguro põe em risco a vida de um grande número de mulheres e representa um grave problema de saúde pública, porquanto são as mulheres mais pobres e jovens as que correm os maiores riscos. A maioria dos óbitos, problemas de saúde e lesões podem ser evitados" (UNFPA, 1995).
} 
corpo foi encontrado carbonizado, sem os dentes e impressões digitais no Rio de Janeiro. Jandira deixou marido e duas filhas.

Mortes como essa, no entanto, são evitáveis segundo a OMS (Organização Mundial da Saúde), que considera o aborto um procedimento seguro, desde que realizado dentro dos protocolos estabelecidos e por pessoas capacitadas. Feito com técnicas e cuidados adequados, pesquisas indicam (RAYMOND; GRIMES, 2012) que o risco de morte por aborto é quase 14 vezes menor do que durante um parto.

Segundo a OMS (2013), até a $20^{\mathrm{a}}$ semana há duas formas seguras de interrupção da gravidez: via procedimentos cirúrgicos ou medicamentosos. No contexto de criminalização, onde a maioria das latino-americanas não tem acesso a clínicas (que significam alto custo), a segunda via, com o uso do Misoprostol ou Misoprostol combinado com Mifepristona, surge como mais acessível e seguro.

Também conhecido pelos nomes comerciais Cytotec, Mibetec, Cyprostol, Misotrol, Arthrotec e Oxaprost, o medicamento atua gerando um estímulo que causa a maturação do colo e contrações do útero, induzindo, desse modo, o abortamento. O Misoprostol consta na lista de medicamentos essenciais da OMS (2017), protocolo que serve de guia de referência para muitos países.

A segurança do método ocorre porque as mulheres ficam menos expostas a instrumentos cortantes e substâncias cáusticas capazes de perfurar o útero e outros órgãos ou de causar danos permanentes à saúde da mulher (BARBOSA; ARILHA, 1993). Estudos também indicam que há menos riscos de infecção quando o aborto é induzido com o uso do Misoprostol (FAÚNDES ET AL, 1996).

Apesar das evidências científicas citadas, o composto tem venda proibida ou restrita na maior parte dos países da América Latina, o que, segundo o CLACAI (Consorcio Latinoamericano Contra el Aborto Inseguro), viola os direitos das mulheres:

Do ponto de vista jurídico, os Estados estão obrigados a respeitar, proteger e garantir o direito de acesso aos avanços científicos, assim como aos demais direitos das usuárias dos serviços de saúde que se veem afetadas pela falta de acesso a esses medicamentos para proteger a sua saúde reprodutiva. Do ponto de vista da finalidade do Estado, os atores estatais estão violando o princípio e o direito à dignidade de todas as mulheres, já que a falta de acesso a meios para controlar a reprodução e proteger sua vida e sua saúde tem como consequência a 
instrumentalização das mulheres. (MICHEL; NAVARRETE, 2017, p. 38., tradução nossa)

Desse modo, os Estados da região negam suporte clínico necessário e acesso a tecnologias eficazes de interrupção da gestação. Deixam sob risco apenas uma parcela da população: mulheres, mas, sobretudo, as pobres negras e indígenas.

No México, por exemplo, em média 36\% dos abortos resultam em complicações que exigem cuidados médicos. Tal proporção, no entanto, sobe para $45 \%$ entre mulheres rurais pobres e cai para $26 \%$ no caso das urbanas das classes média e alta (JUÁREZ et al, 2013).

Por sua vez, pesquisa de Emanuelle Gois (2018) mostrou como racismo se manifesta no acesso à atenção hospital pós-aborto no Brasil. Segundo a autora, mulheres pretas e pardas apresentam maiores dificuldades na busca de cuidados para o primeiro atendimento pósaborto e estão expostas à situação de vulnerabilidade. Em relação às brancas, mulheres pretas entrevistadas citaram mais barreiras como "não ter dinheiro para transporte" e "medo de ser maltratada no serviço", enquanto as pardas diziam que não tinham com quem deixar os filhos. Gois também constatou que mulheres negras chegaram em piores condições de saúde ao hospital e informaram ter enfrentado empecilhos institucionais para internação.

Também pesquisa de Maria Luisa Heilborn et al. (2012) apontou como os processos de tomada de decisão e os itinerários até a realização do aborto são distintos entre jovens de classes médias e populares no Brasil. As primeiras costumam ter o apoio emocional e financeiro da família e procuram clínicas seguras para o procedimento, já as pobres se arriscam muitas vezes sozinhas em chás e se submetem às "curiosas" (como são chamadas popularmente as mulheres que realizam abortos).

Tal situação pode ser exemplificada pela história de Thainá, de 24 anos, coletada durante a pesquisa de Heilborn. Moradora do Rio de Janeiro, sem emprego formal e com ensino fundamental incompleto, a jovem foi submetida a procedimentos perigosos, que quase lhe custaram a vida, conforme relata Heilborn et al. (2012, p. 174, grifo do autor):

$\mathrm{Na}$ tentativa de aborto, primeiramente ela toma Misoprostol; sem sucesso, procurou uma "curiosa". A sonda utilizada perfurou os rins e $\mathrm{o}$ intestino. $\mathrm{O}$ feto sobreviveu sem sequelas. Thainá ficou em coma por três dias e afirma que "quase morreu". Vivendo em um relacionamento 
violento, ela se separa do parceiro. Aos 21 anos, engravida de novo, em uma relação sexual ocasional. Mais uma vez, faz uso de diversos procedimentos para interromper a gestação: chás de "buchinha do norte", de maconha, de cachaça com arruda, de cogumelo fervido com vinho, de folha de café; Misoprostol, mas nada funcionou. Foi então que recorreu a outra "curiosa", que utilizou um líquido e talo de mamona. Vinte e quatro horas depois de ter feito o procedimento, passando muito mal, com cólica e febre, resolveu ir para o hospital: umas duas a três horas do negócio já em mim, eu já comecei a sentir cólica... sangrando, aí começou a me dar febre. Fui parar no hospital [...] Me deu convulsão, até então eu tava naquela que o feto ia descer... E o feto já estava morto dentro de mm e eu não sabia. Devido a ele já estava morto, a dor veio, mas eu num..., ele tava agarrado na placenta.

Os autores ainda afirmam que o hospital público se recusou a recebê-la e seu pai teve que acionar a polícia para que o atendimento fosse realizado.

Nesse contexto de criminalização, que como já demonstrado afeta a maior parte das pessoas na América Latina, são características como raça, renda, acesso à informação e localização geográfica que determinam se uma mulher terá um itinerário abortivo mais ou menos rápido e seguro. Por isso, discutir a legalização do aborto exige um debate que incorpore questões como racismo, machismo e acesso de serviços de saúde públicos e gratuitos.

\section{Impactos Sociais e Econômicos da Criminalização}

Cada vez que uma pessoa morre ou tem a saúde prejudicada por um aborto malsucedido, perdem-se profissionais, mães, filhas, estudantes, que podiam gerar renda, que sustentavam outras pessoas, que tinham famílias, histórias e planos para o futuro.

Na América Latina, a taxa de mortalidade por aborto é de 10 para cada 100 mil nascidos vivos. Na Europa, onde a maior parte dos países legalizou a prática, a proporção cai para 1 a cada 100 mil nascidos vivos. (FAÚNDES; SHAH, 2015). Só na Argentina, 30 mulheres morreram por conta de um aborto inseguro em 2017 (DEIS, 2018).

Mas não são as mortes que mais custam às sociedades. Todos os anos, gastos com procedimentos pós-aborto inseguros sobrecarregam os sistemas públicos de saúde. Só no Brasil, R \$ 40,4 milhões do orçamento 
do SUS (Sistema Único de Saúde) foi para a realização de curetagens e AMIU (aspiração manual intrauterina) em 2015 (AOS FATOS, 2016). Esse valor, no entanto, não engloba custos com cirurgias ou tratamentos para infecções resultantes de um aborto inseguro.

Em toda a América Latina, estima-se que, por ano, sejam gastos 113 milhões de dólares com procedimentos pós-aborto (VLASSOFF ET AL, 2008). Não por acaso, mortalidade materna e legislação sobre aborto são itens avaliados pelo Fórum Econômico Mundial para a elaboração do relatório de desigualdade de gênero em 144 países (WORLD ECONOMIC FORUM, 2016).

Além dos impactos financeiros, negar o direito à interrupção segura de uma gestação compromete o potencial de parte das futuras gerações na América Latina. Exemplo disso é o caso de uma menina de 10 anos, $34 \mathrm{~kg}$ e $1,39 \mathrm{~m}$ de altura, que havia sido violentada pelo padrasto e teve o aborto negado no Paraguai (CUÉ, 2015). E esse não é um caso isolado.

No México, Lamas (2017, p. 301) usa o caso de Mónica para mostrar as dificuldades que passam meninas, especialmente as pobres e indígenas, para ter acesso a um aborto legal e seguro, mesmo em caso de estupro:

Mónica, de 12 anos, é uma indígena mazateca de Oaxaca, e não fala espanhol. Ficou grávida após ser estuprada por um conhecido. Ao denunciar a violação ao Ministério Público, ela solicitou a interrupção da gravidez em conformidade com a legislação penal local. Apesar do Ministério Público ter outorgado a autorização, Mónica enfrentou diversos obstáculos, como falta de recursos necessários para o transporte para o hospital público e a hospedagem na cidade de Oaxaca, assim como a ausência de tradutores durante o processo penal e também durante a prática médica. Finalmente, a gravidez foi interrompida.

Segundo o Fundo de Populações das Nações Unidas (UNFPA, 2013), em todo o mundo, 3,2 milhões de abortos são realizados por ano em jovens com menos de 18 anos de forma insegura. Ainda de acordo com o órgão, 200 meninas morrem por dia em todo mundo por complicações da gravidez precoce.

As que decidem fazer um aborto ilegal têm mais chances de complicações, como hemorragias, lesões em órgãos internos, tétano, infecções, esterilidade e morte, do que as mulheres adultas que usam os 
mesmos procedimentos (UNFPA, 2013). Por outro lado, as meninas que optam por manter a gestação são expostas a riscos durante o parto, têm maior chance de repetência e abandono escolar, e perdem as oportunidades de desenvolvimento pessoal e profissional (UNFPA, 2013). Há ainda os impactos na vida social e psicológica.

Na maior parte da América Latina, a elas é negado o direito de decidir quando e quantos filhos gerar, e a encruzilhada entre os riscos de manter ou interromper de forma insegura uma gestação representa bem a realidade das crianças e adolescentes que engravidam precocemente na Região. Mas há ainda um agravante: em países como Guatemala, Paraguai e Peru, elas são impedidas de interromper a gestação até quando esta é resultado de um estupro. Em 2019, o Congresso do Equador chegou a rejeitar um projeto que descriminalizava o aborto nesses casos.

Sem respaldo jurídico para um aborto legal, o quadro nesses países é o que o Comitê Latino-americano e do Caribe para a Defesa dos Direitos da Mulher (CLADEM) chama de "gravidez infantil forçada", ou seja, quando uma menina fica grávida sem que o tenha desejado e a ela é negada, dificultada ou são colocados obstáculos à interrupção da gestação. Diz a organização:

Se a gravidez dura 9 meses, a maternidade dura toda a vida e as transforma de maneira transcendental. Obrigar uma menina que não terminou de crescer a levar a termo uma gravidez, ser mãe e criar um bebê deve ser considerada tortura ou tratamento cruel, desumano e degradante, segundo os casos, nos termos da Convenção Contra a Tortura e Outros Tratamentos ou Penas Cruéis, Desumanos ou Degradantes, e do Pacto Internacional de Direitos Civis e Políticos. (CLADEM, 2016, p. 8, tradução nossa)

\section{Aborto Legal e Seguro: um passo para a Igualdade Social e de Gênero}

Se é crítico o contexto atual da criminalização do aborto na América Latina, a inspiração para mudanças a fim de garantir o exercício pleno dos direitos reprodutivos de mulheres e meninas pode vir dos próprios países da Região. No passado, por exemplo, o Código Penal da Argentina foi um dos primeiros do mundo a despenalizar o aborto em caso de estupro, em 1922, e serviu de inspiração para as reformas penais 
que ocorrem em seguida no Brasil, no México, no Uruguai e em Cuba (HTUN, 2010).

É importante citar também que o Misoprostol, desenvolvido inicialmente para o tratamento e a prevenção da úlcera gástrica, teve efeito abortivo primeiro identificado pelas mulheres no Brasil (BARBOSA; ARILHA, 1993). No país, o composto começou a ser vendido em 1986 e rapidamente passou a ser adotado de modo informal pelas mulheres e depois por profissionais de saúde para essa finalidade em outros países do mundo.

De acordo com Regina Maria Barbosa e Margareth Arilha (1993), que investigaram o uso do remédio pelas brasileiras entre o final da década de 1980 e o início dos anos 1990, as vendas do medicamento dispararam no Brasil já nos primeiros anos após o registro pelo Ministério da Saúde, exatamente porque se difundiu pelo país como método seguro, barato e fácil de realizar um aborto.

Esse processo resultou em uma verdadeira cruzada contra o medicamento que acabou determinando a mudança da regulamentação da sua comercialização pelo Ministério da Saúde, em julho de 1991, na tentativa de restringir o seu uso como abortificiente. [...] Em 1991, o laboratório Biolab admite que 'a utilização do medicamento para a indução do aborto (...) pode chegar a $35 \%$ do total'. Estima-se, entretanto, que esta proporção seja muito maior. (BARBOSA, ARILHA, 1993, p. 411)

No campo Legislativo, avanço recente foi a mudança na lei do Chile, em vigor desde setembro de 2017, que permite a interrupção legal da gestação em três situações no Chile: inviabilidade fetal, estupro e risco de morte para a mãe. O texto foi apresentado pelo Executivo em janeiro de 2015, enfrentou dois anos e meio de debates no Congresso e um julgamento pelo Tribunal Constitucional até ser promulgado pela presidenta Michelle Bachelet. As possibilidades legais ainda são tímidas, é verdade, mas tirou o Chile dos países mais restritivos do mundo, já que até então vigorava uma lei que proibia o aborto em todos os casos.

Na mesma linha, a Câmara dos Deputados da Bolívia aprovou no fim de 2017 uma lei que descriminaliza o aborto até a $8^{\mathrm{a}}$ semana de gestação para as mulheres que sejam estudantes ou tenham sob seus cuidados crianças, idosos ou pessoas deficientes.

Merece menção também a legalização do aborto no Uruguai, em 2012. No país, após a mudança da lei, foram realizados 9.719 
procedimentos desse tipo em 2016 e 9.830 em 2017, o que contribuiu para a taxa de zero mortes gestantes por aborto no período (REPÚBLICA ORIENTAL DEL URUGUAY, 2018). Além disso, o Uruguai, que chegou a despenalizar a prática entre 1934 e 1938 (SAPRIZA, 1997), atualmente associa o sistema de aborto legal a programas de educação sexual e reprodutiva e de acesso a métodos contraceptivos. A interrupção da gestação só é oferecida nos serviços públicos e gratuitos do país.

No México, onde o tema é legislado pelos Congressos de cada Estado, o aborto é permitido até a $12^{\mathrm{a}}$ semana de gestação desde 2007 no Distrito Federal e, desde 2019, em Oaxaca. No início de 2019, havia 13 clínicas de aborto legal que ofereciam o serviço de maneira gratuita na Cidade do México, além das instituições privadas autorizadas a realizar o procedimento. Até o final do mesmo ano, os deputados de Oaxaca ainda não haviam aprovado uma lei para regulamentar esse tipo de atendimento nos hospitais públicos.

O caso da Cidade do México tornou-se emblemático para todo o país. Aprovado em 2007 pela Congresso local, o texto foi questionado por grupos conservadores na Suprema Corte, que acabou por julgá-lo constitucional no ano seguinte. Essa derrota causou uma reação articulada nos demais Estados do país para impedir a aprovação de leis parecidas. A antropóloga mexicana Marta Lamas (2017, p. 156) narra que, assim que foi promulgada a despenalização do aborto na capital federal, partidos como PAN (Partido Ação Nacional) e o PRI (Partido Revolucionário Institucional) adotaram como estratégia reformar as constituições de outros Estados para incluir "a proteção da vida desde o momento da concepção" . O primeiro a fazer a mudança foi o Estado de Sonora, seguido por Morelos, Baja California, Colima, Puebla, Jalisco, Durango e Nayararit -todos em 2008-e mais onze unidades federativas até 2017.

A Marea Verde iniciada na Argentina, no entanto, deu impulso a uma nova fase de disputas pela legalização do aborto nos Estados, e a grande vitória foi a mudança na lei de Oaxaca em 2019.

Nos casos em que o Legislativo não abre espaço para esse debate, os tribunais têm sido uma alternativa na América Latina. Na Colômbia (2006), por exemplo, a Corte Constitucional despenalizou o aborto em caso de risco para a saúde física e mental da mulher, má formação fetal e estupro. No Brasil (2012), o STF considerou legal a antecipação voluntária do parto em caso de anencefalia fetal. Ainda no Brasil, está 
em pauta no STF (2017) uma ação que pede a descriminalização da prática até a $12^{\mathrm{a}}$ semana de gestação.

Por fim, a força dos pañuelos verdes levou à aprovação, em junho de 2018, do projeto de lei que descriminaliza o aborto até a $14^{\mathrm{a}}$ semana de gestação pela Câmara dos Deputados da Argentina. Apesar das seis tentativas anteriores, esta foi a primeira vez que um texto da Campaña Nacional por el Derecho al Aborto Legal sobre o tema chegou ao plenário do Congresso.

O texto não foi aprovado no Senado (2018), onde sofreu a forte pressão conservadora, mas gerou um amplo debate nos meios de comunicação, nas escolas, nos serviços de saúde, nos sindicatos, entre outros espaços, aumentando a legitimidade da prática. Segundo pesquisas realizadas à época da votação, mais da metade da população da Argentina era a favor da interrupção legal da gestação (PALADINI, 2018).

Isso contribuiu para avançar na desconstrução do tabu que costuma envolver a experiência aborto, como afirmou a jornalista e feminista Mariana Carbajal (2018) no jornal Pagina12 no dia seguinte à votação no Senado, e pode servir de inspiração para feministas de outros países da América Latina:

Ganamos, porque el aborto dejó de ser un tabú y salió del closet y se despenalizó socialmente. Ganamos, porque las madres y las abuelas les contaron a sus hijas y nietas sobre sus abortos, porque las adolescentes llevaron el debate a sus hogares y a las escuelas. Ganamos, porque el mundo nos miró y descubrió que en la Argentina las mujeres todavía no tenemos el derecho a decidir sobre nuestros cuerpos y quedamos vergonzosamente expuestos como un país donde todavía no gozamos de ciudadanía plena. Nunca nos regalaron nada. [...] Los votos que faltaron para despenalizar y legalizar el aborto no son más que una piedra en el camino. No fue ayer. Será mañana.

\section{Referências}

ARGENTINA (2018). Senado de La Nación. Proyecto de Ley Interrupción Voluntaria del Embarazo. Buenos Aires, 13 de jun. 2018. Disponível em <http://www.senado.gov.ar/parlamentario/parlamentaria/406622/ downloadPdf $>$ Acesso em 30 de dez. 2019. 
AOS FATOS (2016). SUS atende 100 vezes mais casos pós-aborto do que faz interrupções legais. UOL, 10 de mar. 2016. Disponível em <https:// noticias.uol.com.br/cotidiano/ultimas-noticias/2016/03/10/sus-atende-100vezes-mais-casos-pos-aborto-do-que-faz-interrupcoes-legais.htm> Acesso em 30 de dez. 2019.

BARBOSA, Regina Maria, \& ARILHA, Margareth (1993). A experiência brasileira com o Cytotec. Revista Estudos Feministas, ano 1, v. 2.

BERTHO, Helena (2017). Vítima do aborto ilegal - Há três anos, Jandira era sepultada após um aborto ilegal. Seu assassinato virou símbolo do debate no Brasil. UOL. Universa. Disponível em <https://www.uol/estilo/especiais/ vitima-do-aborto-ilegal.htm\#vitima-do-aborto-ilegal > Acesso em 30 de dez. 2019.

BRASIL (2012). Supremo Tribunal Federal. Argüição de descumprimento de preceito fundamental 54. Brasília, 12 de abr. 2012. Disponível em <http:// redir.stf.jus.br/paginadorpub/paginador.jsp?docTP $=\mathrm{TP} \& d o c I D=3707334>$ Acesso em 30 de dez. 2019.

CARBAJAL, Mariana. Ganamos. Pagina12. Buenos Aires, 9 de ago. 2018 (versão online). Disponível em <https://www.pagina12.com.ar/134081ganamos $>$ Acesso em 30 de dez. 2019.

CENTER FOR REPRODUCTIVE RIGHTS (2018). The World Abortion Laws. Disponível em <http://worldabortionlaws.com> Acesso em 30 de dez. 2019.

CENTENERA, Mar (2017). Absuelta una joven argentina que estuvo dos años presa por un aborto. El País, 28 de mar. 2017. Disponível em <https:// elpais.com/internacional/2017/03/27/argentina/ 1490648400_185209.html> Acesso em 30 de dez. 2019.

COLÔMBIA (2006). Corte Constitucional. Sentencia C-355, de 10 de maio. Disponível em <http://www.alcaldiabogota.gov.co/sisjur/normas/ Norma1.jsp?i=21540 > Acesso em 30 de dez. 2019.

COMITE LATINO-AMERICANO E DO CARIBE PARA A DEFESA DOS DIREITOS DA MULHER [CLADEM] (2016). Niñas Madres. Embarazo y maternidad infantil forzada en América Latina y el Caribe. Balance Regional. Disponível em < https://cladem.org/publicaciones/balance-regional-ninasmadres/> Acesso em 30 de dez. 2019. 
CUÉ, Carlos (2015). Paraguai impede o aborto de uma menina violada de 10 anos e 34 quilos. El País, 5 de mai., 2015. Disponível em <https:// brasil.elpais.com/brasil/2015/o5/o5/internacional/ 1430843506_403313.html> Acesso em 30 de dez. 2019.

DEIS (2018). Estadísticas vitales. Información básica, año 2017. Dirección de Estadísticas e Información en Salud, Ministerio de Salud de la Nación. Disponível em < http://www.deis.msal.gov.ar/wp-content/uploads/2019/o1/ Serie5Nro61.pdf $>$ Acesso em 30 de dez. 2019.

DINIZ, Debora (2007). Aborto e Saúde Pública no Brasil. Caderno de Saúde Pública. Rio de Janeiro, v. 23, n. 9, p. 1992-1993.

FAÚNDES, A., SANTOS, L.C., CARVALHO, M., \& GRAS, C. (1996) Postabortion complications after interruption of pregnancy with misoprostol. Advances in Contraception, n. 12, v. 1, mar. 1996, p. 1-9.

FAÚNDES, Aníbal, SHAH, Iqbal H. (2015). Evidencia que apoya un mayor acceso al aborto legal y seguro. International Journal of Gynecology and Obstetrics, n. 131.

FONDO DE POBLACIÓN DE LAS NACIONES UNIDAS [UNFPA] (2013). Informe del Estado de la Poblacion Mundial 2013, Maternidad en la ninez: Afrontar el desafio de un embarazo adolescente. Nova York. Disponível em <https://www.unfpa.org/sites/default/files/pub-pdf/ES-SWOP2013.pdf> Acesso em 30 de dez. 2019.

FUNDO DE POPULAÇÃO DAS NAÇÕES UNIDAS [UNFPA] (1994). Conferência Internacional sobre População e Desenvolvimento (CIPD). Plano de Ação. Cairo. Disponível em <http://unfpa.org.br/Arquivos/relatoriocairo.pdf $>$ Acesso em 30 de dez. 2019.

FUNDO DE POPULAÇÃO DAS NAÇÕES UNIDAS [UNFPA] (1995). Declaração e Plataforma de Ação da IV Conferência Mundial Sobre a Mulher. Pequim. Disponível em <http://www.unfpa.org.br/Arquivos/ declaracao_beijing.pdf $>$ Acesso em 30 de dez. 2019.

GANATRA, B., GERDTS, C., ROSSIER, C., JOHNSON JR, B., TUNÇALP, Ö., ASSIFI, A., SEDGH, G., SINGH, S., BANKOLE, A., POPINCHALK, A., BEARAK, J., KANG, Z., \& ALKEMA, L. (2017). Global, regional, and subregional classification of abortions by safety, 2010-14: estimates from a Bayesian hierarchical model. The Lancet. v. 390, n. 10110, 25 Nov. 2017. 
GÓES, Emanuelle (2018). Racismo, aborto e atenção à saúde: uma perspectiva interseccional. Tese (Doutorado em Saúde Pública) Universidade Federal da Bahia. Salvador.

GUTTMACHER INSTITUTE (2016). Hoja informativa: Aborto en América Latina y Caribe. Disponível em <https://www.guttmacher.org/sites/default/ files/factsheet/fs-aww-lac-es.pdf > Acesso em 30 de dez. 2019.

HTUN, Mala (2010). Sexo y Estado: aborto, divorcio y familia bajo dictaduras y democracias en America Latina. Santiago: Ediciones Universidad Diego Portales.

JUÁREZ, Fatima, SING, Susheela, MADDOW-ZIMET, Isaac, WULF, Deirdre (2013). Embarazo no planeado y aborto inducido en México: causas y consecuencias. Nova York, Guttmacher Institute, 2013.

LA CONTROVERTIDA sentencia de 30 años de cárcel contra Evelyn Hernández, la joven que parió a un bebé muerto tras ser violada por un pandillero en El Salvador. BBC, 7 de jul. 2017. Disponível em <https:// www.bbc.com/mundo/noticias-40534010> Acesso em 30 de dez. 2019.

LAMAS, Marta (2017). La interrupción legal del embarazo. El caso de la Ciudad de México. México: FCE, UNAM, CIEG.

MICHEL, Agustina, NAVARRETE Sonia (2017). Entre la indolencia y el sesgo: el derecho de las mujeres a beneficiarse de los avances científicos en materia reproductiva. Consorcio Latinoamericano Contra el Aborto Inseguro - CLACAI. Lima.

ORGANIZAÇÃO MUNDIAL DA SAÚDE [OMS] (2013). Abortamento seguro: Orientação Técnica e de Políticas para Sistemas de Saúde. Genebra. Disponível em <http://apps.who.int/iris/bitstream/ 10665/70914/7/9789248548437_por.pdf> Acesso em 30 de dez. 2019.

ORGANIZAÇÃO MUNDIAL DA SAÚDE [OMS] (2017). 2oth WHO Model List of Essential Medicines. Genebra. Disponível em <http://www.who.int/ medicines/publications/essentialmedicines/en/\#> Acesso em $30 \mathrm{de}$ dez. 2019.

PALADINI, Eduardo. Dos nuevas encuestas sobre el aborto, a horas de que arranque el debate. Clarín, 8 de abr. 2018. Disponível em <https:// 
www.clarin.com/politica/nuevas-encuestas-aborto-horas-arranquedebate_o_rkAj4JusG.html> Acesso em 30 de dez. 2019.

RAYMOND, E. G., GRIMES, D. A. The comparative safety of legal induced abortion and childbirth in the United States. In: Obstetrics \& Gynecology, fev. 2012.

REPÚBLICA ORIENTAL DEL URUGUAY. Uruguay no registra casos de mortalidad materna por interrupción voluntaria del embarazo. Montevideu, 29 de mai. 2018. Disponível em <https://www.presidencia.gub.uy/ comunicacion/comunicacionnoticias/dia-internacional-salud-mujeres-jorgebasso-canelones-mortalidad-materna-casi-cero> Acesso em 30 de dez. 2019.

SAPRIZA, Graciela (1997). Entre o desejo e a norma: A despenalização do Aborto no Uruguai, 1934-1938. In: COSTA, Albertina de Oliveira (org.). Direitos tardios: saúde, sexualidade e reprodução na América Latina. São Paulo: PRODIR/FCC.

SENADO DE LA NACIÓN (2018). Proyecto de ley Interrupción Voluntaria del Embarazo. Buenos Aires, 13 de jun. 2018. Disponível em <http:// www.senado.gov.ar/micrositios/ive/4> Acesso em 30 de dez. 2019.

SUPREMO TRIBUNAL FEDERAL (2017). Arguição de Descumprimento de Preceito Fundamental 442. Número único: oo02062-31.2017.1.00.0000. Relatora: ministra Rosa Weber. Disponível em <http://portal.stf.jus.br/ processos/detalhe.asp?incidente $=5144865>$ Acesso em 30 de dez. 2019.

URUGUAY (2012). Ley $N^{\circ}$ 18987. Ley sobre interrupción voluntaria del embarazo. Ley del aborto. Montevideo, 22 dic. 2012. Disponível em <https:// www.impo.com.uy/bases/leyes/18987-2012> Acesso em 30 de dez. 2019.

VLASSOFF, Michael, SHEARER, Jessica, WALKER, Damian, LUCAS, Henry (2008). Economic Impact of Unsafe Abortion-Related Morbidity and Mortality: Evidence and Estimation Challenges. IDS Research Report, n. 59

WORLD ECONOMIC FORUM (2017). The Global Gender Gap Report 2017. Genebra. Disponível em <http://www3.weforum.org/docs/ WEF_GGGR_2017.pdf > Acesso em 30 de dez. 2019.

ZIELINSKA, E., MÉNDEZ, J., PŪRAS, D., ŠIMONOVIĆ, D., GIAMMARINARO, M. G., \& GAER, F. Gender-based crimes through the lens of torture International Women's Day - Tuesday, 8 Mar. 2016. Genebra, 3 de 
mar. 2016. Disponível em <http://www.ohchr.org/EN/NewsEvents/Pages/ DisplayNews.aspx?NewsID=17152\&LangID=E $>$ Acesso em 30 de dez. 2019. 


\section{Para un futuro de igualdad en América Latina, el derecho de decidir}

RESUMEN: Este ensayo discute como la criminalización del aborto es uno de los grandes obstáculos para el pleno ejercicio de la ciudadanía por las mujeres en América Latina. Desde una revisión bibliográfica y de casos discutidos recientemente en el Judiciario y el Legislativo de países la Región, muestra porque la legalización del aborto es un tema emergente para garantizar la igualdad de género en nuestras sociedades. El texto enumera aun los impactos de la criminalización de la práctica en la salud pública, en la economía y el en vida de un $97 \%$ de las mujeres latinoamericanas. En fin, el ensayo apunta conquistas y caminos ya recurridos en países de la Región como forma de pensar un futuro de cambios en América Latina.

PALABRAS ClavE: Aborto. Igualdad de Género. América Latina.

Marcelle Cristine de SOUZA

Jornalista, mestra e doutoranda no PROLAM-USP (Programa de Pósgraduação Interunidades Integração da América Latina da Universidade de São Paulo). Bolsista Capes.

Recebido em: 06/01/2019

Aprovado em: 30/12/2019 